\title{
A Bitter Pill: Formulary Variability and the Challenge to Prescribing Physicians
}

\author{
William H. Shrank, MD, MSHS, Susan L. Ettner, PhD, Peter Glassman, MBBS, MSc, \\ and Steven M. Asch, MD, MPH
}

Background: Multitiered, incentive-based formularies have been increasingly used as a mechanism to control prescription drug expenditures. Prescribing physicians who manage patients from multiple insurers must be familiar with the variability in their patients' formulary incentives to help patients choose therapy wisely. However, the degree of formulary variability among and within health plans over time is unclear.

Methods: In 6 major health plans in California, we evaluated formulary incentive variability in 4 of the 5 drug classes with the highest expenditures in California: proton pump inhibitors, hydroxymethylglutaryl coenzyme A reductase inhibitors ("statins"), calcium channel blockers, and angiotensin-converting enzyme inhibitors. We categorized 20 branded members of these classes into either "preferred" or nonpreferred/uncovered categories. We calculated the consistency that brands were preferred across health plans and the frequency of changes in formulary status for each drug within plans between 2000 and 2002.

Results: None of the branded drugs evaluated were preferred on all formularies in 2002 , and $10 \%$ were not available on any of the formularies. Formulary status varied greatly across plans, and more than $60 \%$ of drugs were preferred on 2 to 4 of the 6 formularies studied. Formulary status within health plans varied between 2000 and 2002 in more than half of the plans in the drug classes evaluated.

Conclusions: In the drug classes evaluated, over a 2 -year period, considerable variability was seen among and within formularies over time. This variability poses a challenge to physicians who wish to reduce patients' expenditures by prescribing the least expensive among similarly effective drugs within a drug class. This variability is especially relevant because recent legislation increases the likelihood that more Medicare beneficiaries will receive their medications from private health plans. (J Am Board Fam Pract 2004;17:401-7.)

The recent trend of using patient cost-sharing in pharmaceutical benefit plans to control the costs of prescription drugs has increased pressure on patients, and hence physicians, to be aware of patient's costs when prescribing. Three-tier pharmacy benefit structures are now the dominant system of providing prescription drugs to Ameri-

Submitted, revised, 12 July 2004.

From the Division of General Internal Medicine, VA Greater Los Angeles Health Care System, Los Angeles, CA 90073 (WHS, PG, SMA), and the Division of General Internal Medicine and Health Services Research, University of California, Los Angeles (SLE, PG, SMA). Address correspondence to William Shrank, MD, VA Greater Los Angeles Health Care System, Division of General Internal Medicine (111G), 11301 Wilshire Blvd, Los Angeles, CA 90073 (e-mail: william.shrank@med.va.gov).

This work was supported by a health services research and development fellowship from the Department of Veterans Affairs (to WHS). cans; ${ }^{1,2} 57 \%$ of Americans with prescription drug coverage were enrolled in 3-tier plans in 2002. ${ }^{3}$ Physicians who desire to serve as agents for their patients and prescribe the least expensive among similarly effective medications must be familiar with the cost-sharing arrangements and formularies offered to each patient by the insurer at the time of prescribing.

Formularies traditionally offered restricted lists of medications available to patients. Of late, most plans offer open formularies, or preferred lists, in which the majority of medications are available, but gradations in co-pays are used to steer patients toward medications that are deemed more costeffective (or preferred) by insurers. In 3-tier benefit plans, insurers require higher co-payments from patients for "nonpreferred," or third-tier, brandname drugs, with lower copayments for preferred 
branded drugs (second tier) and the lowest copayments for generic drugs (first tier).

The typical physician sees patients from many health plans, ${ }^{1}$ each offering its own pharmacy benefits plan with its own formulary. In 2001, physicians who had at least one managed care contract managed patients from an average of 13.1 plans. $^{4}$ Hence, most physicians have to deal with more than a dozen formularies when prescribing.

Physicians, when prescribing, play the unique role of a learned intermediary for their patients. They are tasked with determining the appropriate treatment for their patients, decisions that are also associated with significant financial consequences. A physician's ability to prescribe the lowest tier medication among similarly effective options in a drug class can dramatically impact patient out-ofpocket expenditures. ${ }^{5}$ Copayments for nonpreferred drugs increased by $62.5 \%$ from 2000 to 2002 , from an average of $\$ 16$ to an average of more than $\$ 26 .^{6}$ Almost half of the costs of prescription drugs in this country are paid out of pocket. ${ }^{7} \mathrm{Fa}-$ miliarity with the medications offered on a patient's formulary is therefore integral to controlling the patient's out-of-pocket costs while prescribing appropriate medications.

A wealth of research has demonstrated that even small increases in copayments for medications lead to decreased patient compliance with prescribed medications. ${ }^{8-12}$ As a result, prescribing a patient the preferred formulary drug not only reduces the patient's out-of-pocket expenditures but also may have significant effects on the patient's adherence to treatment regimens. ${ }^{13}$

As formulary variability increases, either between or within formularies over time, so too does the challenge physicians face when attempting to identify the least expensive medication for a particular patient within a class of similarly effective medications. To date, no quantitative work has been published that describes the degree of variability that physicians must confront when prescribing from patient's formularies.

Herein, we attempt to describe formulary variability in large health plans in California. A single region was evaluated to represent the challenge that an individual physician might face when navigating patient formularies in a typical practice setting. California was chosen as the locus of the study because it offers a conservative representation of the challenges faced by providers, in that recent
Table 1. Top 5 Expenditures in California, by Drug Class, in 1999

\begin{tabular}{ll}
\hline Drug Class & $\begin{array}{l}\text { Expenditures } \\
\text { in California }\end{array}$ \\
\hline Proton-pump inhibitors and H2 antagonists & $\$ 564,670,000$ \\
Selective serotonin-reuptake inhibitors & $\$ 541,234,000$ \\
Statins & $\$ 501,528,000$ \\
CCBs & $\$ 326,658,000$ \\
ACE inhibitors & $\$ 271,670,000$ \\
\hline
\end{tabular}

consolidation of large health plans has helped to reduce variability of drug plans.

\section{Methods}

Formularies of 6 of the 7 largest California health plans (in terms of enrollment) were assessed. All 7 health plans represented approximately $86 \%$ of managed care enrollment in California in 2001. ${ }^{14}$ Kaiser Permanente was excluded because physicians in their network manage only Kaiser patients and are required to be familiar with only one formulary. The remaining 6 health plans comprise approximately $57 \%$ of managed care enrollment in California and approximately $80 \%$ of non-Kaiser managed care enrollment. ${ }^{14}$ Formularies from the dozens of other smaller California health plans were not evaluated.

Formulary variability was evaluated in 4 of the top 5 classes of drugs as ranked by dollars spent on prescription drugs in California in $1999^{15}$ (Table 1). The classes evaluated included protonpump inhibitors, hydroxymethylglutaryl-coenzyme A reductase inhibitors (statins), dihydropyridine calcium-channel blockers (CCBs), and angiotensinconverting enzyme (ACE) inhibitors. Each drug class is commonly used for medical problems seen in general or family practice and includes multiple branded agents with similar clinical efficacy and safety profiles. Selective serotonin receptor inhibitors were excluded because mental health services are often provided as part of a carved-out portion of a patients' insurance plan, and the source, payment, and formulary coverage of mental health medications can be complicated and more difficult to identify.

Formulary coverage of the 4 drug classes in the fall/winter of 2000 in 6 health plans were evaluated and compared with formulary coverage in the winter of 2002 to 2003. Only "preferred," single- 


\begin{tabular}{|c|c|c|c|c|c|c|c|c|}
\hline \multirow[b]{2}{*}{ Proton-Pump Inhibitor } & \multirow[b]{2}{*}{ Blue Shield } & \multirow[b]{2}{*}{ Aetna } & \multirow[b]{2}{*}{ HealthNet } & \multirow[b]{2}{*}{ Pacificare } & \multirow[b]{2}{*}{ Blue Cross } & \multirow[b]{2}{*}{ Cigna } & \multicolumn{2}{|c|}{$\begin{array}{l}\text { Total Formularies } \\
\text { Offering Drug in }\end{array}$} \\
\hline & & & & & & & 2000 & 2002 \\
\hline Aciphex (rabeprazole) & $00 / 02^{*}$ & $00 / 02$ & $00 / 02$ & $00 / 02$ & NP & 02 & $4 / 6$ & $5 / 6$ \\
\hline Nexium (esomeprazole) & NP & NP & NP & NP & NP & NP & $0 / 6$ & $0 / 6$ \\
\hline Prevacid (lansoprazole) & NP & $00 / 02$ & NP & NP & $00 / 02$ & $00 / 02$ & $3 / 6$ & $3 / 6$ \\
\hline Prilosec (omeprazole) & NP & NP & 00 & NP & NP & NP & $1 / 6$ & $0 / 6$ \\
\hline Protonix (pantoprazole) & $00 / 02$ & NP & $00 / 02$ & $00 / 02$ & 02 & 02 & $3 / 6$ & $5 / 6$ \\
\hline $\begin{array}{l}\text { Number of preferred drugs } \\
\text { Added by plan } \\
\text { Removed by plan }\end{array}$ & $\begin{array}{l}0 \\
0\end{array}$ & $\begin{array}{l}0 \\
0\end{array}$ & $\begin{array}{l}0 \\
1\end{array}$ & $\begin{array}{l}0 \\
0\end{array}$ & $\begin{array}{l}1 \\
0\end{array}$ & $\begin{array}{l}2 \\
0\end{array}$ & & \\
\hline
\end{tabular}

* 00, preferred in 2000; 02, preferred in 2002; NP, nonpreferred in 2000 or 2002.

source brands (those without generic equivalents) from each plan were compared. Branded drugs with generic equivalents were excluded because widespread use of automatic generic substitution protocols has simplified the prescribing process for these medications. It is noteworthy that only 1 of the top 5 classes as ranked by expenditures in California (ACE-I) also fell in the top 5 classes of medication as ranked by utilization, ${ }^{15}$ suggesting that expensive, branded medications are commonly prescribed in the classes evaluated. Branded drugs, in general, represent the overwhelming majority of drug spending in the United States. Although about $42 \%$ of the prescriptions dispensed in the US are for generic drugs, they comprise only $17.9 \%$ of total drug spending. ${ }^{16}$ All health plans evaluated in this study offered 3-tier plans and the second tier of branded options (the preferred drugs) is presented here.

Formulary information was cross-referenced from multiple sources: (1) health plan web sites; (2) written information dispersed to participating patients and physicians; (3) the Triple i California Managed Care Formulary Guide prepared by Medimedia; ${ }^{17}$ and (4) a 2000 report by the California Health Care Foundation. ${ }^{1}$ Brands that require only preferred copayments were generally considered to be preferred in this analysis, even if prior authorization was required. However, if some of the brands within a class required prior authorization and others did not, only those that did not require prior authorization were considered "preferred."

For each class of drugs presented, inter- and intraplan variability were assessed. Interplan variability was determined by assessing the fraction of health plans that conferred preferred status to each branded drug in a given year (2000 or 2002). Intraplan variability was determined by evaluating rates that health plans changed preferred status of medications on their formularies between 2000 and 2002. We noted when preferred medications were either added to or subtracted from health plan formularies.

\section{Results}

\section{Proton-Pump Inbibitors}

Between 2000 and 2002, 5 brands of proton-pump inhibitors were available, none of which had a generic equivalent. No brands were preferred on all major formularies over both time periods (Table 2). However, rabeprazole and pantoprazole were preferred in 5 of the 6 formularies in 2002 and 3 and 4 of the 6 formularies, respectively, in 2000. Lansoprazole was preferred on half of the formularies during both periods. Only one drug, esomeprazole, had no interplan variability, because esomeprazole was not offered as a preferred drug on any formulary in either period. Formulary changes were seen in 3 of the 6 health plans between 2000 and 2002 . Of the plans with formulary changes, only one plan changed a PPI from preferred to nonpreferred status, and the other 2 plans added PPIs to their preferred lists.

\section{Statins}

Five brands without generic alternatives were on the market in 2000. No branded statin was preferred on all formularies during both time periods, and every statin was preferred on at least 2 formularies (Table 3). Lovastatin was available in generic 


\begin{tabular}{|c|c|c|c|c|c|c|c|c|}
\hline \multirow[b]{2}{*}{ Statins } & \multirow[b]{2}{*}{ Blue Shield } & \multirow[b]{2}{*}{ Aetna } & \multirow[b]{2}{*}{ HealthNet } & \multirow[b]{2}{*}{ Pacificare } & \multirow[b]{2}{*}{ Blue Cross } & \multirow[b]{2}{*}{ Cigna } & \multicolumn{2}{|c|}{$\begin{array}{l}\text { Total Formularies } \\
\text { Offering Drug in }\end{array}$} \\
\hline & & & & & & & 2000 & 2002 \\
\hline Lescol (fluvastatin) & $00 / 02^{*}$ & $00 / 02$ & $00 / 02$ & NP & 00 & 02 & $4 / 6$ & $5 / 6$ \\
\hline Lipitor (atorvastatin) & $00 / 02$ & NP & $00 / 02$ & NP & $00 / 02$ & NP & $3 / 6$ & $3 / 6$ \\
\hline Pravachol (pravastatin) & 02 & NP & $00 / 02$ & $00 / 02$ & $00 / 02$ & NP & $3 / 6$ & $4 / 6$ \\
\hline Zocor (simvastatin) & NP & $00 / 02$ & NP & 02 & NP & $00 / 02$ & $2 / 6$ & $3 / 6$ \\
\hline $\begin{array}{l}\text { Number of preferred dr } \\
\text { Added by plan } \\
\text { Removed by plan }\end{array}$ & $\begin{array}{l}1 \\
0\end{array}$ & $\begin{array}{l}0 \\
0\end{array}$ & $\begin{array}{l}0 \\
0\end{array}$ & $\begin{array}{l}1 \\
0\end{array}$ & $\begin{array}{l}0 \\
1\end{array}$ & $\begin{array}{l}1 \\
0\end{array}$ & & \\
\hline
\end{tabular}

* 00, preferred in 2000; 02, preferred in 2002; NP, nonpreferred in 2000 and 2002.

Baycol is not presented here because it was removed from the market for safety reasons.

form on all plans in 2002. All other branded products were available as a preferred medication on 2 to 4 of the 6 formularies in 2000 and from 2 to 5 of the 6 formularies in 2002. Four of the 6 health plans changed their formularies between 2000 and 2002. Only one plan dropped a statin from preferred to nonpreferred status, and the other plans added one statin each.

\section{CCBs}

In this analysis, we evaluated only the dihydropyridines, a subclass commonly used for blood pressure management and angina (Table 4). One drug from this subclass, nifedipine, was available in generic form and was available in one of several forms on all formularies. Only one branded drug, felodipine, was available on all 6 formularies in 2000 and on 5 of the 6 formularies in 2002. All other brands were preferred on 2 to 4 of the 6 formularies during both periods. Intraplan variability evaluation dem- onstrated that 2 of the 6 health plans changed preferred status of at least one CCB; both plans changed a CCB from preferred to nonpreferred status.

\section{ACE Inbibitors}

Two drugs in this class, captopril and lisinopril, were available in generic form and were available on all formularies. No branded drug was preferred on all formularies, and only ramipril was not preferred on any formulary in 2000 (Table 5). Benazepril was available on 5 of the 6 formularies in 2000 and 2002 and ramipril and quinapril were available on 5 of the 6 in 2002. All other brands were preferred on 1 to 4 of the 6 formularies during both periods. Intraplan variability was highest in this class, with 5 of the 6 health plans changing their preferred lists between 2000 and 2002, although all 5 plans added medications to the preferred list and none dropped any brands.

Table 4. Preferred Formulary Placement of Calcium Channel Blockers

\begin{tabular}{|c|c|c|c|c|c|c|c|c|}
\hline \multirow[b]{2}{*}{ CCBs } & \multirow[b]{2}{*}{ Blue Shield } & \multirow[b]{2}{*}{ Aetna } & \multirow[b]{2}{*}{ HealthNet } & \multirow[b]{2}{*}{ Pacificare } & \multirow[b]{2}{*}{ Blue Cross } & \multirow[b]{2}{*}{ Cigna } & \multicolumn{2}{|c|}{$\begin{array}{l}\text { Total Formularies } \\
\text { Offering Drug in }\end{array}$} \\
\hline & & & & & & & 2000 & 2002 \\
\hline Cardene (nicardipine) & $\mathrm{NP}^{*}$ & 02 & NP & $00 / 02$ & NP & 00 & $2 / 6$ & $2 / 6$ \\
\hline Dynacirc (isradipine) & NP & NP & NP & $00 / 02$ & $00 / 02$ & $00 / 02$ & $3 / 6$ & $3 / 6$ \\
\hline Norvasc (amlodipine) & NP & $00 / 02$ & $00 / 02$ & $00 / 02$ & $00 / 02$ & $\mathrm{NP}$ & $4 / 6$ & $4 / 6$ \\
\hline Plendil (felodipine) & $00 / 02$ & 00 & $00 / 02$ & $00 / 02$ & $00 / 02$ & $00 / 02$ & $6 / 6$ & $5 / 6$ \\
\hline Sular (nisoldipine) & $00 / 02$ & NP & $00 / 02$ & $00 / 02$ & $00 / 02$ & $\mathrm{NP}$ & $4 / 6$ & $4 / 6$ \\
\hline $\begin{array}{l}\text { Number of preferred drugs } \\
\text { Added by plan } \\
\text { Removed by plan }\end{array}$ & $\begin{array}{l}0 \\
0\end{array}$ & $\begin{array}{l}1 \\
1\end{array}$ & $\begin{array}{l}0 \\
0\end{array}$ & $\begin{array}{l}0 \\
0\end{array}$ & $\begin{array}{l}0 \\
0\end{array}$ & $\begin{array}{l}0 \\
1\end{array}$ & & \\
\hline
\end{tabular}

* 00, preferred in 2000; 02, preferred in 2002; NP, nonpreferred in 2000 or 2002. 


\begin{tabular}{|c|c|c|c|c|c|c|c|c|}
\hline \multirow[b]{2}{*}{ ACE Inhibitors } & \multirow[b]{2}{*}{ Blue Shield } & \multirow[b]{2}{*}{ Aetna } & \multirow[b]{2}{*}{ HealthNet } & \multirow[b]{2}{*}{ Pacificare } & \multirow[b]{2}{*}{ Blue Cross } & \multirow[b]{2}{*}{ Cigna } & \multicolumn{2}{|c|}{$\begin{array}{l}\text { Total Formularies } \\
\text { Offering Drug in }\end{array}$} \\
\hline & & & & & & & 2000 & 2002 \\
\hline Accupril (quinapril) & $\mathrm{NP}^{*}$ & $00 / 02$ & $00 / 02$ & 02 & $00 / 02$ & $00 / 02$ & $4 / 6$ & $5 / 6$ \\
\hline Altace (ramipril) & NP & 02 & 02 & 02 & 02 & 02 & $0 / 6$ & $5 / 6$ \\
\hline Lotensin (benazepril) & $00 / 02$ & NP & $00 / 02$ & $00 / 02$ & $00 / 02$ & $00 / 02$ & $5 / 6$ & $5 / 6$ \\
\hline Mavik (trandolapril) & NP & 02 & NP & 02 & $00 / 02$ & $00 / 02$ & $2 / 6$ & $4 / 6$ \\
\hline Monopril (fosinopril) & $00 / 02$ & NP & $00 / 02$ & $00 / 02$ & NP & $00 / 02$ & $4 / 6$ & $4 / 6$ \\
\hline Univasc (moexipril) & NP & NP & 02 & $00 / 02$ & NP & 02 & $1 / 6$ & $3 / 6$ \\
\hline $\begin{array}{l}\text { Number of preferred } \\
\text { Added by plan } \\
\text { Removed by plan }\end{array}$ & $\begin{array}{l}0 \\
0\end{array}$ & $\begin{array}{l}2 \\
0\end{array}$ & $\begin{array}{l}2 \\
0\end{array}$ & $\begin{array}{l}3 \\
0\end{array}$ & $\begin{array}{l}1 \\
0\end{array}$ & $\begin{array}{l}2 \\
0\end{array}$ & & \\
\hline
\end{tabular}

* 00, preferred in 2000; 02, preferred in 2002; NP, nonpreferred in 2000 or 2002.

\section{Discussion}

In our study of large California health insurers, we found significant variability between formularies offered by large health plans and within health plans over time. When interplan variability (variability across plans) was assessed, we found that $65 \%$ of the brands evaluated in 2000 were available as a preferred medication on 2 to 4 of the 6 formularies. In 2002, 60\% were preferred on 2 to 4 formularies. On the other hand, only $5 \%$ in 2000 and $0 \%$ in 2002 were available on all formularies, and $10 \%$ were never available in either 2000 or 2002 (Fig. 1). We conclude that exceedingly few medications are preferred on all or no formularies, and most branded products are preferred inconsistently.

From a prescribing physician's perspective, predicting formulary placement is much easier when a medication is either always preferred or never preferred and much more challenging when inconsistently preferred on patient formularies. Our anal-

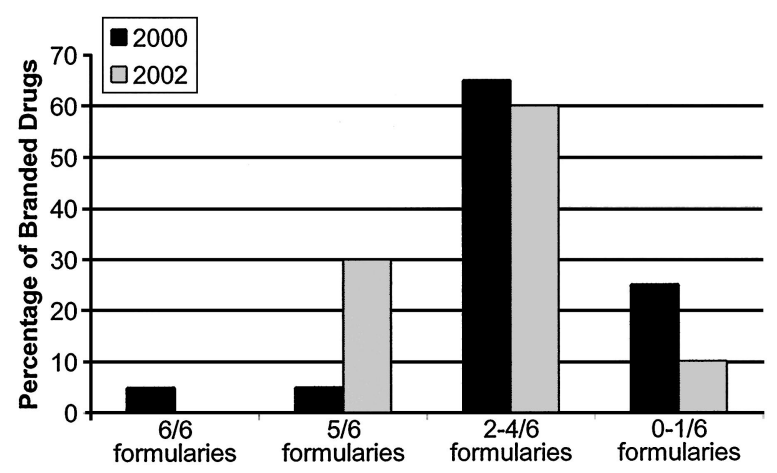

Figure 1. Preferred formulary placement of branded drugs in large California health plans. ysis suggests that physicians who hope to serve as agents for their patients and prescribe the preferred medication within a class of similarly effective drugs face a difficult task when attempting to identify that preferred drug.

Intraplan variability (variability within plans over time) was also appreciable, with formulary changes seen in more than half of the health plans $(54 \%)$ in the 4 classes of drugs evaluated. For the most part, formularies have tended to include more brands in 2002 than they did in 2000. On the average, one of the 6 health plans dropped a branded drug from preferred to nonpreferred status in the drug classes studied.

Intraplan variability, although notable, probably creates less of an impediment for prescribing physicians. Physicians face a challenge when health plans remove a branded drug from a preferred list, forcing physicians who have already prescribed that medication to patients on that plan to switch the medication to one with less out-of-pocket cost requirements. Although more than half of the plans changed the preferred status of at least one brand in each class, the majority of the changes were additions, not subtractions, from the preferred lists. Although it is probably difficult for physicians to track health plan formulary coverage, patients are likely to be affected only when health plans drop coverage of a brand, which we saw in about 1 of every 6 health plans for each drug class between 2000 and 2002.

We do not attempt in this article to depict the full complexity of the prescribing process for physicians. First, physicians typically see patients from more than twice the number of health plans eval- 
uated in this study. We also evaluated only 4 drug classes. There are hosts of other drug classes with multiple branded options that have similar clinical efficacy (eg, oral contraceptives, inhaled steroids, angiotensin receptor blockers, etc) that are difficult for physicians to prescribe. In addition, some employers choose a health plan to manage health services but carve out pharmaceutical services to a specialized pharmacy benefits manager that offers its beneficiaries a different, unique formulary. Different insurers also require prior authorization for certain drugs, with variability among plans. These complexities all affect patient out-of-pocket costs and place further burdens on physicians trying to adhere to patient's formularies.

Physicians who aspire to help patients manage out-of-pocket costs and attempt to prescribe preferred formulary medications must either be familiar with (or check) the formulary agent(s) offered by the insurer at the time of prescribing. Otherwise, if that is not the case, any changes must be made later, for example at the point of dispensing. Thus, the responsibility of adhering to formularies has been shifted to the pharmacist, insurer, or patient, requiring additional contact with the clinician's office in any case. A recent study confirmed that private clinicians report that adherence to patient's formulary medicine was often dependent on a pharmacist's feedback with patient information and that proactive checking of the formulary list was rarely relied on. ${ }^{18}$

Complex pharmacy benefit structures and formulary variability force us to collectively consider what systems may facilitate formulary compliance for prescribers. Software programs (eg, Epocrates) are currently available at no charge for physicians with handheld PDA devices and contain formulary information from a number of insurers. However, a recent survey indicated that only $30 \%$ of physicians use PDA systems, ${ }^{19}$ and many health plans do not currently list their formularies on Epocrates, forcing the consideration of alternative strategies. Another electronic option is simplified, one-stop web access to formulary information, although this depends on the clinician's access to the Internet at the time of patient consultation. Formulary handbooks that present formulary information specific to a physician's practice location are already in use, but in dealing with multiple formularies, the clinician must have ready access to those resources as well as the willingness and time to use them during patient encounters. Many have suggested that electronic prescribing would ultimately provide immediate feedback to prescribers about formulary information and would simplify formulary compliance for prescribers. $^{20}$

The issue of formulary variability and the challenges faced by prescribing physicians is especially pressing with the recent passage of a Medicare prescription drug benefit. The Medicare legislation advocates the use of private health plans to play a major role in disseminating prescription drugs to seniors. Older patients disproportionately use prescription drugs. Among those over the age of 65 who filled at least one prescription, the average utilization of prescription drugs was more than 23 prescriptions annually in $2000 .{ }^{4}$ We must consider ways to ensure that seniors who receive their medications from complex, multitiered pharmaceutical benefit structures are assisted as they navigate through their formularies and copay requirements to identify the least expensive of similarly effective medications for their medical problems. A more standardized formulary for our seniors could simplify the prescribing process for both physicians and patients. However, the recent Medicare legislation specifically prohibited the government from negotiating drug prices for seniors. Instead, we must rely on our current market system in which individual insurers negotiate privately for lower prescription drug prices or higher rebates from pharmaceutical manufacturers in return for preferred formulary status and, hence, higher volume of sales. As long as drug prices are controlled by private negotiations between insurers and manufacturers, formulary variability will probably continue to be a challenge for prescribing physicians.

\section{Conclusion}

The current system of providing prescription drugs to patients in the private sector relies on costsharing and formulary placement to create incentives to control costs. To help patients manage their out-of-pocket costs, physicians must prescribe their patient's preferred medications from their insurer's formulary. In California, great variability is seen among preferred medications offered by large insurers and within plans over time. A physician faces a challenge when prescribing if he/she intends to serve as a financial agent for the patient and prescribe the least expensive among similarly effec- 
tive and safe medications. This challenge may influence patient out-of-pocket expenditures and compliance with medication and might be especially difficult for elderly patients who take many medications.

\section{References}

1. William Mercer, Inc. Prescription drug coverage and formulary use in California: differing approaches and emerging trends [monograph on the Internet]. Oakland (CA): California Healthcare Foundation; 2001 [cited 2003 Dec 2]. Available from: http:// www.chcf.org/topics/view.cfm?itemID $=12658$.

2. Curtiss FR. Perspectives: drugs, PPOs, tiered cost share for beneficiaries and consumer preferences. J Manag Care Pharm 2002;8:192-7.

3. Kaiser Family Foundation and Health Research and Educational Trust. Employer health benefits: 2002 summary of findings [monograph on the Internet]. Menlo Park (CA): Kaiser Family Foundation; 2002 [cited 18 Nov 2003]. Available from: http://www. kff.org/insurance/3252-index.cfm.

4. Strunk BC, Reschovsky JD. Kinder and gentler: physicians and managed care, 1997-2001. Tracking report no. 5 [monograph on the Internet]. Washington (DC): Center for Studying Health Systems Change; 2002 [cited 21 Nov 2003]. Available from: http://www.hschange.com/CONTENT/486/?topic= topic03.

5. Joyce GF, Escarce JJ, Solomon MD, Goldman DP. Employer drug benefit plans and spending on prescription drugs. JAMA 2002;288:1733-9. Erratum in: JAMA 2002;288:2409.

6. Kaiser Family Foundation and Health Research and Educational Trust. Survey of employer-sponsored health benefits: 2000, 2001, 2002 [monograph on the Internet]. Menlo Park (CA): Kaiser Family Foundation; 2002. Available from: http://www.kff.org/ insurance/3251-index.cfm.

7. Medical Expenditure Panel Survey Highlights. Distribution of healthcare expenses, 1996. MEPS Highlights \#11. Publication no. 00-0024. Rockville (MD): Agency for Healthcare Research and Quality; 2000. Available from: http://www.meps.ahrq.gov/ papers/hl11_00-0024/hl11.pdf

8. Hillman AL, Pauly MV, Escarce JJ, et al. Financial incentives and drug spending in managed care. Health Aff (Millwood) 1999;18:189-200.

9. Stuart B and Zacker C. Who bears the burden of
Medicaid drug copayment policies. Health Affairs 1999;18:201-12.

10. Smith DG. The effects of copayments and generic substitution on the use and costs of prescription drugs. Inquiry 1993;30:189-98.

11. Reeder CE, Nelson AA. The differential impact of copayment on drug use in a Medicaid population. Inquiry 1985;22:396-403.

12. Harris BL, Stergachis A, Reid A. The effect of drug co-payments on utilization and cost of pharmaceuticals in a health maintenance organization. Med Care 1990;28:907-17.

13. Huskamp HA, Deverka PA, Epstein AM, Epstein RS, McGuigan KA, Frank RG. The effect of incentive-based formularies on prescription-drug utilization and spending. N Engl J Med 349:2224-32.

14. Baumgarten A. California managed care review 2002 [monograph on the Internet]. Oakland (CA): California Healthcare Foundation; 2002 [cited 3 Dec 2003]. Available at: http://www.chcf.org/topics/ view.cfm?itemID $=20119$

15. Bymark L, Waite K. Prescription drug use and expenditures in California: key trends and drivers [monograph on the Internet]. Oakland (CA): California Healthcare Foundation; 2001 [cited 1 Dec 2003]. Available from: http://www.chcf.org/topics/ view.cfm?itemID $=12656$

16. Kaiser Family Foundation and Health Research and Educational Trust. Prescription drug trends: a chartbook update [monograph on the Internet]. Menlo Park (CA): Kaiser Family Foundation; 2001 [cited 30 Apr 2004]. Available from: http://www.kff.org/ rxdrugs/loader.cfm?url=/commonspot/security/getfile. cfm\&PageID $=13796$.

17. Triple i managed care formulary guide, California, Fall 2002/Winter 2003. Teterboro (NJ): Medimedia USA, Inc.; 2002.

18. Glassman PA, Tanielian T, Harris K, et al. Provider perceptions of pharmacy management: lessons from the military health system. Med Care 2004;42: 361-6.

19. Buckley M. Improving drug prescribing practices in the outpatient setting: a market analysis [monograph on the Internet]. Oakland (CA): California Healthcare Foundation; 2002 [cited 9 Nov 2003]. Available from: http://www.chcf.org/topics/view.cfm? itemID $=20184$.

20. Corley ST. Electronic prescribing: a review of costs and benefits. Top Health Inf Manage 2003;24: $29-38$. 